\title{
O estatuto jurídico das águas no Brasil
}

\author{
FER NANDO MUSSA ABUJAMRA AITH ${ }^{I}$ \\ e RENATA ROTHBARTH ${ }^{I I}$
}

\section{Introdução}

A

ÁGUA, recurso natural da Terra, essencial para a sobrevivência do ser humano, vem se tornando um bem de alto valor social e econômico.

A regulação jurídica das águas vem sendo progressivamente reformada para responder às evidências cada vez mais alarmantes no que se refere a esse recurso natural. Recentemente, a Organização Mundial nas Nações Unidas publicou previsões em seu último Relatório das Nações Unidas sobre o Desenvolvimento da Água 2015, sendo uma delas a de que "até 2030, o planeta enfrentará um déficit de água de $40 \%$, a menos que seja melhorada dramaticamente a gestão desse recurso" (Unesco, 2015).

Estima-se que o Brasil concentre entre $12 \%$ e $16 \%$ do volume total de recursos hídricos do planeta. Segundo dados apresentados até o momento, existe abundância de água no norte, região com aproximadamente $5 \%$ da população nacional onde estão concentrados $73 \%$ da disponibilidade hídrica brasileira. Enquanto isso, os restantes $95 \%$ da população dividem $27 \%$ dos recursos hídricos do país (Esteves, 2012, p.24).

A importância das águas no globo como um todo, e no Brasil especificamente, resultou na aprovação de um expressivo conjunto de normas jurídicas nacionais e internacionais visando regular as atividades humanas relacionadas a esse bem, que passa a ser cada vez mais juridicamente tutelado. Essas normas, embora esparsas e pouco articuladas entre si, permitem a identificação, se compreendidas em seu conjunto, de um Estatuto Jurídico das Águas no Brasil, conforme será apresentado neste artigo.

Para construir o desenho do que aqui denominamos como Estatuto Jurídico das Águas no Brasil, foram pesquisadas e analisadas as normas jurídicas internacionais e nacionais que tratam direta ou indiretamente das águas, com enfoque na identificação, nessas normas, dos seguintes elementos: i) grau de reconhecimento jurídico formal da água como um direito humano fundamental no Brasil e no direito internacional; ii) regime constitucional das águas no Brasil; iii) natureza jurídica das águas no direito interno e; iv) garantias jurídicas para a proteção do direito à água. A pesquisa foi realizada nas páginas oficiais do governo brasileiro e da Organização das Nações Unidas, e as normas selecionadas foram aquelas vi- 
gentes e que apresentam conteúdo relevante para a construção teórica do Estado Jurídico das Águas.

\section{Direito humano fundamental à água}

O reconhecimento normativo formal de um direito é o primeiro passo para a sua proteção, mas não será efetivo sem que haja um efetivo esforço dos governos e das sociedades para que esse reconhecimento formal se transforme em ações capazes de garantir o direito reconhecido para todos. No que se refere à água, o seu reconhecimento como um direito humano fundamental é um fenômeno relativamente recente e ainda carente de contornos bem definidos.

Desde 1966 a Organização das Nações Unidas (ONU) menciona em seus documentos a água como um bem jurídico a ser protegido. O Pacto dos Direitos Econômicos, Sociais e Culturais de 1966 (ONU, 1966), ratificado pelo Brasil em 1992, afirma que todos os povos podem dispor livremente de suas riquezas e de seus recursos naturais e que em caso algum poderá o povo ser privado de seus próprios meios de subsistência. A água, naturalmente, insere-se como um bem essencial para a subsistência humana e foi protegida por esse dispositivo, ainda que de forma genérica.

Em 1977, a Conferencia das Nações Unidas sobre Água aprovou o Plano de Ação de Mar del Plata, estipulando os objetivos de identificar o status das fontes de água no globo, assegurar um nível adequado de água para as necessidades socioeconômicas do planeta, aumentar a eficiência na gestão da água e evitar a crise de abastecimento de água potável em dimensões globais antes do final do século XX (ONU, 1977).

A década de 1980 foi extremamente importante no processo de afirmação histórica do direito à água. Intitulada pelas Nações Unidas como "Década da Água Potável" o período compreendido entre 1981 e 1990 foi o início de uma conscientização a respeito dos efeitos da poluição e do desperdício de água sobre o bem-estar do homem, sobretudo para os países menos desenvolvidos (Kaufman, 2012).

A Conferência Internacional sobre Água e Meio Ambiente organizada pela ONU em janeiro de 1992, na cidade de Dublin (Irlanda), tratou pela primeira vez da necessidade de cada país em exercer uma eficiente "gestão de recursos hídricos", partindo do princípio de que "a escassez e o mau uso da água doce são fatores de grande e crescente risco ao desenvolvimento sustentável e à proteção do meio ambiente" (ONU, 1992a). O resultado dessa conferência foi a chamada Declaração de Dublin, documento que estabeleceu quatro princípios básicos que reconhecem: I) que a água doce é um bem finito e essencial para a continuidade da espécie humana; II) a necessidade de uma abordagem participativa para gerenciamento da água, envolvendo a participação cidadã e dos Estados em todos os seus níveis legislativos; III) o papel preponderante da mulher na provisão, gerenciamento e proteção da água; IV) o reconhecimento da água como bem econômico. 
Nesse mesmo ano, realizou-se também a Conferência das Nações Unidas sobre Meio Ambiente e Desenvolvimento, no Rio de Janeiro, conhecida também como Rio 92, Eco-92 ou ainda, Cúpula da Terra. Dentre os resultados mais expressivos desse evento, destaca-se a Agenda 21, definida como "um instrumento de planejamento para a construção de sociedades sustentáveis, em diferentes bases geográficas, que concilia métodos de proteção ambiental, justiça social e eficiência econômica" (ONU, 1992b). No que diz respeito às recomendações para o desenvolvimento sustentável da água, constam o Capítulo 17, que versa sobre a proteção de oceanos, de todos os tipos de mares - incluindo mares fechados - e das zonas costeiras, e o Capítulo 18, sobre a qualidade, aplicação e manejo dos recursos hídricos.

A água como direito humano foi propriamente reconhecida pela Organização Mundial das Nações Unidas em julho de 2010. A Resolução A/ RES/64/292 declarou "a água limpa e segura e o saneamento (como) um direito humano essencial para gozar plenamente a vida e todos os outros direitos humanos" (ONU, 2010). Para além disso, a Resolução também incentiva os Estados e organizações internacionais a fornecerem assistência e cooperação na forma de capacitação, recursos financeiros e transferência de tecnologia, notadamente para os países em desenvolvimento, a fim de intensificar os esforços para um fornecimento igualitário de água potável, limpa e disponível para todos.

Desde 2002 o Comitê das Nações Unidas para Direitos Econômicos, Sociais e Culturais envida esforços para inserir o direito à água como direito humano, vide o comentário geral n.15 que afirma: "O direito humano à água prevê que todos tenham água suficiente, segura, aceitável, fisicamente acessível e a preços razoáveis para usos pessoais e domésticos” (ONU, 2015).

Ainda que esses documentos internacionais não possuam caráter vinculativo do ponto de vista jurídico, a ONU não tem medido esforços para que os Estados passem a reconhecer em seus ordenamentos jurídicos internos o direto à água como um direito humano. Dessa forma, o órgão internacional defende que todos merecem ter acesso contínuo e suficiente à água para usos pessoais e domésticos, devendo esse ser utilizado e preservado de maneira sustentável tanto para as presentes quanto para as futuras gerações.

É nesse contexto jurídico internacional que o Brasil vem formatando os contornos jurídicos de proteção da água, a começar pelos dispositivos previstos na Constituição de 1988. Como se verá, embora as águas contem com ampla regulação jurídica, o reconhecimento do direito humano fundamental à água ainda é frágil em nossa legislação interna constitucional ou infraconstitucional.

\section{Regime constitucional das águas}

No Brasil, a proteção jurídica das águas tem suas bases estabelecidas pela Constituição Federal de 1988 (CF 88), que tratou da matéria em dispositivos esparsos ao longo de seu texto (Brasil, 1988). O Estatuto Jurídico das Águas no Brasil tem suas bases na CF 88 e abrange, de um lado, a proteção dos direitos 
humanos e, de outro, a proteção do meio ambiente e dos recursos hídricos e naturais.

No que se refere à proteção dos direitos humanos, a proteção jurídica das águas é uma consequência natural do reconhecimento constitucional de direitos humanos fundamentais, tais como a vida, a segurança, a dignidade, a saúde, a alimentação, o consumidor e a cidadania (Castro, 2010, p.30). O acesso à água potável, a coleta e o tratamento de esgotos, a gestão responsável dos recursos hídricos pelo Estado, a preservação das nascentes, dentre outros direitos, representam uma extensão natural desses direitos e garantias fundamentais reconhecidos expressamente pela CF 88.

A indivisibilidade dos direitos humanos foi expressamente prevista pela Declaração de Viena de 1992, que afirma em seu artigo 5 que "todos os direitos do homem são universais, indivisíveis, interdependentes e inter-relacionados" (ONU, 1992c). Fica, portanto, evidente a relação jurídica indivisível da água com alguns dos mais relevantes direitos fundamentais reconhecidos pela CF 88, como a vida, a saúde ou o meio ambiente equilibrado: não há que falar em direito à vida digna sem água potável e meio ambiente equilibrado; não há como garantir a saúde das pessoas sem acesso à água potável e ao tratamento de esgotos; não há como garantir a segurança sanitária sem um abastecimento adequado de água potável à população.

No que se refere à proteção do direito ao meio ambiente equilibrado, o artigo 225 da CF 88 prevê o direito de todos a um meio ambiente ecologicamente equilibrado, que passa a ser considerado "bem de uso comum do povo essencial à sadia qualidade de vida, impondo-se ao Poder Público e à coletividade o dever de defendê-lo e preservá-lo para as presentes e futuras gerações" (Brasil, 1988). Nesse sentido, a Constituição prevê que as condutas e atividades consideradas lesivas ao meio ambiente sujeitam os infratores a sanções civis, administrativas e penais, especificadas em legislação infraconstitucional.

De acordo com a CF 88, é da União a competência privativa para legislar sobre águas e energia, podendo uma lei complementar autorizar os Estados a também o fazerem sobre questões específicas da matéria. O artigo 23, XI, da CF 88 , prevê que aspectos relacionados a registro, acompanhamento e fiscalização das concessões e explorações de recursos hídricos, por sua vez, são de competência concorrente entre a União, os estados, o distrito federal e os municípios. Vê-se que, ainda que a União possua preponderância na normatização sobre águas no país, existe uma descentralização federativa relevante no que diz respeito a aspectos estratégicos da regulação do uso e exploração dos recursos hídricos, tornando extremamente complexa a gestão das águas no país.

Há ainda outros dispositivos da CF 88 voltados à regulação das águas no Brasil. O artigo $43, \$ 2^{\circ}$, prevê incentivos regionais para que se priorize o aproveitamento econômico e social dos rios e das massas de água represadas ou represáveis em regiões de baixa renda e que sofrem secas periódicas. Já o artigo 
200 encarrega o Sistema Único de Saúde de fiscalizar as bebidas para consumo humano, inclusive a água. Por fim, resta positivado na atual Constituição que o aproveitamento e autorização para exploração de recursos hídricos em terras indígenas necessita de aprovação prévia do Congresso Nacional.

Percebe-se, assim, que a $\mathrm{CF} 88$, embora não reconheça expressamente a água como um direito humano fundamental, oferece um conjunto de dispositivos que garantem uma proteção especial a este bem jurídica e constitucionalmente tutelado.

\section{Natureza jurídica das águas no Brasil}

A CF 88 caracteriza a água como um bem público juridicamente tutelado. No Estado federado brasileiro, há uma divisão da titularidade das águas entre a União e os estados. O artigo 20, inciso III, da CF 88, dispõe que pertencem à União "os lagos, rios e quaisquer correntes de água em terrenos sob seu domínio, ou que banhem mais de um estado, que sirvam de limites com outros países, que provenham ou se estendam a território estrangeiro e também os terrenos marginais e as praias fluviais" (Brasil, 1988, art. 20).

O inciso VIII do mesmo artigo 20 da CF 88 dispõe também pertencer à União os potenciais de energia hidráulica existentes no país, sendo, nesse caso, assegurada aos estados, ao distrito federal e aos municípios, bem como a órgãos da administração direta da União, a compensação financeira ou participação no resultado da exploração de recursos hídricos, seja para fins de geração de energia elétrica, seja de outros recursos minerais no respectivo território, plataforma continental, mar territorial ou zona econômica exclusiva. Assim, compete ao governo federal explorar, diretamente ou mediante autorização, concessão ou permissão "os serviços e instalações de energia elétrica e o aproveitamento energético dos cursos de água, em articulação com os Estados onde se situam os potenciais hidroenergéticos".

As águas também podem ser de titularidade dos estados-membro da federação brasileira, nos casos previstos pelo artigo 26 da CF 88:

Art. 26. Incluem-se entre os bens dos Estados:

I - as águas superficiais ou subterrâneas, fluentes, emergentes e em depósito, ressalvadas, neste caso, na forma da lei, as decorrentes de obras da União;

II - as áreas, nas ilhas oceânicas e costeiras, que estiverem no seu domínio, excluídas aquelas sob domínio da União, Municípios ou terceiros;

III - as ilhas fluviais e lacustres não compreendidas entre as da União. (Brasil, 1988)

Sendo a titularidade das águas da União ou dos estados-membros, a natureza jurídica das águas no Brasil é a de bem público.

De acordo com os artigos 99 a 103 do Código Civil brasileiro, são públicos os bens do domínio nacional pertencentes às pessoas jurídicas de direito público interno, como é o caso das águas (Brasil, 2002). Os bens públicos, incluindo as 
águas, podem ter três diferentes tipos de uso, conforme a sua finalidade e relevância pública: I - de uso comum do povo, tais como rios, mares, estradas, ruas e praças; II - de uso especial, tais como edifícios ou terrenos destinados a serviço ou estabelecimento da administração federal, estadual, territorial ou municipal, inclusive os de suas autarquias; III - os dominicais, que constituem o patrimônio das pessoas jurídicas de direito público, como objeto de direito pessoal, ou real, de cada uma dessas entidades. Não dispondo a lei em contrário, consideram-se dominicais os bens pertencentes às pessoas jurídicas de direito público a que se tenha dado estrutura de direito privado. Os bens públicos de uso comum do povo e os de uso especial são inalienáveis, enquanto conservarem a sua qualificação, na forma que a lei determinar. Os bens públicos dominicais podem ser alienados, observadas as exigências da lei. O uso comum dos bens públicos pode ser gratuito ou retribuído, conforme for estabelecido legalmente pela entidade a cuja administração pertencerem.

Assim, embora a natureza jurídica das águas no Brasil seja a de bem público, o uso desse bem pode ser classificado conforme a finalidade e o modelo de gestão estatal que se dê. Em qualquer caso, no entanto, a proteção da água para consumo humano e animal, bem como o acesso à água potável para subsistência são determinantes sobre a gestão dos recursos hídricos no Brasil e condicionantes do uso da água no país.

\section{Garantias jurídicas do direito à água no Brasil}

Fixado o entendimento de que a água se caracteriza como um direito humano fundamental, é importante compreender quais são as garantias jurídicas efetivas criadas pelo Estado para a proteção do direito reconhecido. Ou seja, uma vez reconhecido o direito, é necessário criar instrumentos jurídicos, administrativos e orçamentários que assegurem a plena fruição do direito reconhecido.

Conforme bem salientado por Jorge Miranda, os direitos representam, por si só, certos bens que devem ser protegidos pelo Estado e pela sociedade, enquanto as garantias destinam-se a assegurar a fruição desses bens; os direitos são principais, as garantias são acessórias e, muitas delas, adjetivas (ainda que possam ser objeto de um regime constitucional substantivo); os direitos permitem a realização das pessoas e inserem-se direta e imediatamente, por isso, nas respectivas esferas jurídicas, as garantias só nelas se projetam pelo nexo que possuem com os direitos; na acepção jusracionalista inicial, os direitos declaram-se, as garantias estabelecem-se (Miranda, 1998, p.88 e 89).

Dentre as garantias jurídicas estabelecidas para o direito humano à água no Brasil destacam-se neste estudo: i) o dever do Estado de fazer a gestão responsável das águas nacionais; ii) a Política Nacional de Recursos Hídricos; iii) a Política Nacional de Saneamento Básico.

\section{Gestão das águas como dever do Estado brasileiro}

A gestão das águas como dever do Estado brasileiro representa uma das principais garantias do direito humano fundamental à água. Nesse sentido, des- 
taca-se o atual desenho jurídico no que se refere às competências da União, dos estados, do distrito federal e dos municípios na gestão dos recursos hídricos.

O Quadro 1 apresenta a divisão de competências entre os entes federativos no que se refere à gestão das águas no país:

Quadro 1 - Competências federativas na gestão de recursos hídricos no Brasil

\begin{tabular}{c|c}
\hline ENTE FEDERATIVO & \multicolumn{1}{c}{ COMPETÊNCIA } \\
\hline & - Gerencia a Política Nacional e o Plano Nacional de \\
& Recursos Hídricos; \\
& - Fiscaliza e regula a gestão hídrica no país, junto ao \\
& Ministério do Meio Ambiente e a Agência Nacional de \\
& Águas; \\
- Conselho Nacional de Recursos Hídricos regulamenta & política com a participação do governo federal, estados, \\
União Federal & DF, Setores e Usuários da Sociedade Civil; \\
& - Ferencia comitês de bacias federais ou interestaduais. \\
& Agência a água para consumo humano por meio da \\
&
\end{tabular}

- Responsável pela gestão das águas sob o seu domínio;

- Elabora legislação específica para sua área;

- Organiza o Conselho Estadual de Recursos Hídricos e Estados $\quad$ garante o funcionamento dos comitês de bacia em sua competência;

- Fiscaliza a água para consumo humano por meio da Vigilância Sanitária estadual.

- Integram políticas de saneamento básico, de uso, ocupação e conservação do solo e do meio ambiente com as políticas federal e estaduais de Recursos Hídricos;

Municípios

- Possuem assentos nos Comitês e Bacias Hidrográficas no intuito de promover a articulação intersetorial e federativa das políticas públicas territoriais;

- Fiscaliza a água para consumo humano por meio da Vigilância Sanitária municipal.

- Possui as mesmas competências dos estados e municípios na gestão de seus Recursos Hídricos.

Assim como ocorre em outras áreas, tais como Saúde e Educação, a gestão das águas no Brasil se torna extremamente complexa tendo em vista a divisão federativa de competências estabelecida pela Constituição e legislação complementar, conforme sintetizado na Tabela 1 . O atual arranjo na divisão das competências de gestão dos recursos hídricos no Brasil não define claramente algumas questões estratégicas relacionadas à titularidade das águas (União X estados); ao saneamento básico (estados X municípios) e; fiscalização da água para consumo humano, realizada pelas respectivas vigilâncias sanitárias de cada ente federativo (União X estados X municípios). 
O Estado brasileiro, para dar conta de seu dever de cuidar das águas no Brasil, criou e desenvolveu instituições jurídicas importantes, que necessitam de alto grau de articulação para que atuem de forma eficaz. O Quadro 2 apresenta as principais instituições jurídicas criadas para a gestão das águas no país:

Quadro 2 - Principais instituições jurídicas estatais responsáveis pela gestão da água no Brasil

\begin{tabular}{l|l}
\hline \multicolumn{1}{c|}{ INSTITUIÇÃO } & \multicolumn{1}{c}{ COMPETÊNCIAS } \\
\hline $\begin{array}{l}\text { Agência Nacional das Águas - } \\
\text { ANA }\end{array}$ & $\begin{array}{l}\text { Autarquia responsável por disciplinar a implementação, } \\
\text { operacionalização, controle e avaliação dos instrumentos } \\
\text { de gestão criados pela Política Nacional de Recursos } \\
\text { Hídricos através do Sistema Nacional de Gerenciamento } \\
\text { de Recursos Hídricos. }\end{array}$ \\
\hline $\begin{array}{l}\text { Secretaria de Recursos Hídricos } \\
\text { e Ambiente Urbano - Ministério do } \\
\text { Meio Ambiente }\end{array}$ & $\begin{array}{l}\text { Responsável por implantar políticas públicas que } \\
\text { permitam a preservação de recursos hídricos, águas } \\
\text { doces, bem como biodiversidades aquáticas e acesso à } \\
\text { água potável. }\end{array}$ \\
\hline Maneamento Ambiental - & $\begin{array}{l}\text { Responsável pela formulação e coordenação de } \\
\text { políticas urbanas que ampliem o acesso à serviços de } \\
\text { saneamento no Brasil (leia-se: fornecimento de água, } \\
\text { esgoto e manejo de resíduos sólidos.) }\end{array}$ \\
\hline Comitês de Bacias Hidrográficas & $\begin{array}{l}\text { Dividido em 10 câmaras técnicas é responsável por } \\
\text { analisar propostas de alteração da legislação pertinente a } \\
\text { recursos hídricos; estabelecer diretrizes complementares } \\
\text { para implementação da Política Nacional de Recursos } \\
\text { Hídricos; promover a articulação do planejamento de } \\
\text { recursos hídricos com os planejamentos nacional, } \\
\text { regionais, estaduais e dos setores usuários; arbitrar } \\
\text { conflitos sobre recursos hídricos; deliberar sobre os } \\
\text { projetos de aproveitamento de recursos hídricos cujas } \\
\text { repercussões extrapolem o âmbito dos estados em que } \\
\text { serão implantados; aprovar propostas de instituição de } \\
\text { comitês de bacia hidrográfica; estabelecer critérios gerais } \\
\text { para a outorga de direito de uso de recursos hídricos e } \\
\text { para a cobrança por seu uso; aprovar o Plano Nacional } \\
\text { de Recursos Hídricos e acompanhar sua execução. }\end{array}$ \\
\hline $\begin{array}{l}\text { Fóruns colegiados responsáveis por aprovar o Plano } \\
\text { de Recursos Hídricos de cada Bacia; arbitrar conflitos } \\
\text { pelo uso da água - em primeira instância administrativa; } \\
\text { estabelecer mecanismos e sugerir os valores da } \\
\text { cobrança pelo uso da água na região colegiada. }\end{array}$ \\
\hline
\end{tabular}

Dentre as instituições estatais responsáveis pela gestão das águas no Brasil, vale destacar, no âmbito da União, a Agência Nacional de Águas (ANA), instituída pela Lei n.9.984/2000. Entidade reguladora da utilização das águas de domínio da União, a ANA é uma autarquia especial vinculada ao Ministério 
do Meio Ambiente, com autonomia técnica, administrativa e financeira. À ANA cabe disciplinar a implementação, a operacionalização, o controle e a avaliação dos instrumentos de gestão criados pela Política Nacional de Recursos Hídricos. Dessa forma, seu espectro de regulação ultrapassa os limites das bacias hidrográficas com rios de domínio da União, pois abrange aspectos institucionais relacionados à regulação dos recursos hídricos em âmbito nacional.

Na prática, a ANA desempenha ações de Regulação, apoio à gestão dos recursos hídricos, de monitoramento de rios e reservatórios, de planejamento dos recursos hídricos, além de desenvolver programas e projetos e oferecer um conjunto de informações com o objetivo de estimular a adequada gestão e o uso racional e sustentável dos recursos hídricos.

Outras atividades da ANA são as de estímulo à criação dos comitês de bacias hidrográficas. Compostos por representantes da sociedade civil, dos usuários da água e dos poderes públicos, os comitês desempenham um importante papel nas ações de regulação, pois aprovam a aplicação adequada dos instrumentos de gestão na bacia. Essas entidades proporcionam que se cumpra, de forma descentralizada, a regulação eficiente.

$\mathrm{Na}$ qualidade de órgão regulador, a ANA publica um conjunto expressivo de normas jurídicas para regular o uso dos recursos hídricos no Brasil, visando definir as condições de operação dos reservatórios, públicos ou privados, garantir os usos múltiplos dos recursos hídricos e avaliar a sustentabilidade de obras hídricas com participação de recursos federais.

\section{Politica nacional de recursos hidricos}

A Lei n.9.433/1997 instituiu a Política Nacional de Recursos Hídricos (PNRH), estabelecendo seus fundamentos, objetivos, diretrizes e instrumentos (Brasil, 1997, artigos $1^{\circ}$ a $4^{\text {a }}$ ).

Esse diploma legal reforça o fundamento da água como um bem de domínio público, detalhando que se trata de um recurso natural limitado e dotado de valor econômico. Paulo Afonso Leme Machado (2002, p.414) esclarece que “a dominalidade pública da água, afirmada na Lei n.9.433/97, não transforma o Poder Público federal e estadual em proprietário da água, mas torna-o gestor desse bem, no interesse de todos".

A gestão dos recursos hídricos deve proporcionar os usos múltiplos das águas, de forma descentralizada e participativa, contando com a participação do Poder Público, dos usuários e das comunidades. Um dos fundamentos da Política prevê que, em situações de escassez, o uso prioritário da água é para o consumo humano e dessedentação de animais. Tendo em vista a importância desse bem público e a possibilidade de escassez, a Política Nacional de Recursos Hídricos deve ser formulada, executada e avaliada por meio de gestão democrática, que conte com ampla participação social.

Um fundamento organizativo da PNRH é a fixação da Bacia Hidrográfica como unidade de implementação da Política e de planejamento e gestão do 
Sistema Nacional de Gerenciamento de Recursos Hídricos. A Política Nacional de Recursos Hídricos tem como objetivos: I) assegurar à atual e às futuras gerações a necessária disponibilidade de água, em padrões de qualidade adequados aos respectivos usos; II) a utilização racional e integrada dos recursos hídricos, incluindo o transporte aquaviário, com vistas ao desenvolvimento sustentável e; III) a prevenção e a defesa contra eventos hidrológicos críticos de origem natural ou decorrentes do uso inadequado dos recursos naturais (Brasil, 1997, artigo $2^{\circ}$, incisos I a III).

São instrumentos da PNRH os Planos de Recursos Hídricos, a regionalização, a integração da gestão dos recursos hídricos com a gestão ambiental, a articulação com os usuários e com os planejamentos regionais, estaduais e nacional. No caso de sobreposição de competências, a União deverá se articular com os Esgotados tendo em vista o gerenciamento dos recursos hídricos de interesse comum.

Uma das inovações da Lei foi a regulamentação da cobrança pelo uso dos recursos hídricos. Através da cobrança no uso e exploração da água, três grandes objetivos são buscados, de acordo com o artigo 19 da Lei n.9.433/2000: reconhecer a água como bem econômico e dar uma indicação do seu real valor; incentivar a racionalização do uso da água; obter recursos financeiros para programas previstos nos planos de recursos hídricos (Brasil, 1997).

\section{Saneamento básico}

Uma das principais garantias do direito humano à água é a implementação de uma rede de saneamento básico universal. A Lei n.11.445, de 5 de janeiro de 2007, estabelece diretrizes nacionais para o saneamento básico, definindo-o como o conjunto de serviços, infraestruturas e instalações necessárias: ao abastecimento público de água potável; ao esgotamento sanitário; à limpeza urbana e manejo de resíduos sólidos e; à drenagem e manejo das águas pluviais urbanas (artigo $3^{\circ}$, inciso I). Passados quase vinte anos após a promulgação da Constituição vigente, a Lei n.11.445/2007 foi concebida como uma espécie de "marco regulatório" dos serviços de saneamento básico, com diretrizes e regras coerentes com as múltiplas realidades sociais, ambientais e econômicas do Brasil (Brasil, 2007).

Além de definir uma série de conceitos, como o de saneamento básico e gestão associada e prestação regionalizada, ela também deixa claro que se trata de um complemento à gestão da água no Brasil. Assim, os recursos hídricos não integram os serviços públicos de saneamento básico, sendo que a utilização de recursos hídricos na prestação de serviços públicos de saneamento é, nos termos do artigo $4^{\circ}$ da Lei n.9.433/97, sujeita a outorga de direito de uso e portanto, paga.

A Lei n.11.445/2007 também estabelece diretrizes técnicas para a prestação de serviços de saneamento básico, fixando requisitos mínimos de qualidade, regularidade e continuidade para a prestação dos serviços. A titularidade dos 
serviços de saneamento básico não ficou bem definida pela legislação em vigor, havendo possibilidade de sobreposição de competências entre estados e municípios. Essa indefinição provoca problemas de execução dos serviços, na medida em que o titular do serviço formulará a respectiva política pública de saneamento básico, sendo responsável por regular e executar os serviços diretamente ou por meio de delegação.

Dentre as poucas competências atribuídas à União fica a definição de parâmetros mínimos de portabilidade da água para abastecimento público, tarefa essa executada pelo Ministério da Saúde. Adicionalmente, estabelece condições específicas para o licenciamento ambiental de unidades de tratamento de esgotos e de resíduos gerados pelos processos de tratamento de água e mecanismos de contingência para casos de racionamento de água.

Embora o Brasil tenha avançado bastante na regulação do saneamento básico, os dados demonstram que ainda há muito a se fazer, tanto no que se refere ao abastecimento de água potável quanto no que se refere à coleta e tratamento de esgoto. Os Quadros 3, 4 e 5 apresentam os cinco piores estados brasileiros no que se refere a estes indicadores.

Quadro 3 - Estados com piores índices de abastecimento de água Índice IN055: Índice de atendimento total de água

Equação: população total atendida com abastecimento de água/população total do Estado fornecida pelo IBGE

\begin{tabular}{c|c}
\hline AMAZONAS & $36,16 \%$ \\
\hline RORAIMA & $38,78 \%$ \\
\hline PARÁ & $42,61 \%$ \\
\hline ACRE & $42,61 \%$ \\
\hline MARANHÃO & $53,34 \%$ \\
\hline
\end{tabular}

Fonte: Instituto Trata Brasil.

Vê-se, pelos dados apresentados, que os recursos hídricos no Brasil ainda estão seriamente ameaçados pelas péssimas condições de saneamento básico no país. Grande parte do esgoto sanitário brasileiro é jogada in natura diretamente na natureza, poluindo os rios e mares e prejudicando o acesso aos recursos hídricos. Mesmo se pegarmos os melhores estados no que se refere a coleta e tratamento de esgoto, ainda assim os dados são alarmantes. São Paulo, o estado com maior índice de coleta de esgoto, recolhe $87,36 \%$ de seu esgoto, tratando apenas de $53,34 \%$. O distrito federal, que também figura entre os melhores, coleta $82,73 \%$ e trata $66,13 \%$ (Trata Brasil, 2015). Ou seja, ainda bem aquém do esperado para que a água seja de fato considerada como um direito fundamental. 
Quadro 4 - Estados com piores índices de coleta de esgoto

Índice IN056: Índice de atendimento total de esgoto referido aos municípios atendidos com água.

Equação: população total atendida com esgotamento sanitário/população residente total, segundo o IBGE

\begin{tabular}{c|c}
\hline RORAIMA & $3,63 \%$ \\
\hline PARÁ & $3,75 \%$ \\
\hline AMAZONAS & $4,12 \%$ \\
\hline AMAPÁ & $6,41 \%$ \\
\hline PIAUÍ & $6,64 \%$ \\
\hline
\end{tabular}

Fonte: Instituto Trata Brasil.

Quadro 5 - Estados com piores níveis de tratamento de esgoto Índice IN046: Índice de esgoto tratado referido à água consumida. Equação: volume de água consumido/volume de esgoto tratado

\begin{tabular}{c|c}
\hline PARÁ & $2,82 \%$ \\
\hline RORAIMA & $4,58 \%$ \\
\hline AMAZONAS & $5,63 \%$ \\
\hline MARANHÃO & $5,85 \%$ \\
\hline PIAUÍ & $8,30 \%$ \\
\hline
\end{tabular}

Fonte: Instituto Trata Brasil.il

O conjunto de garantias jurídicas existentes para a proteção da água como um direito humano fundamental mostra-se, no Brasil, ainda bastante precário e insuficiente.

\section{Considerações finais}

O desenho do Estatuto Jurídico das Águas no Brasil demonstra que existe uma considerável fragmentação normativa, sendo necessário acessar um conjunto expressivo de normas jurídicas para que se possam compreender os principais institutos jurídicos que definem e regulam a natureza jurídica, o uso, o gozo e a disposição das águas no país. Com normas vigentes que vão desde o Decreto n.24.643, de 1934, até o marco regulatório de saneamento básico, de 2007, passando pelo conjunto expressivo de normas infralegais exarado pela Agência Nacional de Águas 
e por outras instituições do Poder Executivo, a compreensão do atual quadro regulatório das águas é extremamente complexa. Esse fato dificulta, de um lado, a própria gestão das águas a ser realizada pelo Estado e, de outro lado, a obediência dessas normas por parte dos setores regulados e dos cidadãos.

Também chama a atenção a expressiva fragmentação institucional para a gestão dos recursos hídricos e do saneamento básico no país. As divisões de competências entre a União, os estados, o distrito federal e os municípios não são bem definidas pelas leis e regulamentos, tanto no que se refere ao gerenciamento dos recursos hídricos quanto no que se refere à gestão do saneamento básico. Além disso, em cada ente federativo surgem instituições jurídicas específicas para cuidar de algum aspecto das águas, instituições essas que não necessariamente se articulam de forma adequada. Apenas na União, como visto no Quadro 2, pode-se encontrar um conjunto relevante de instituições competentes para a gestão de algum aspecto específico das águas.

Também chama a atenção o fato de que somente em 2007 o Brasil aprovou o seu marco regulatório do saneamento básico, ainda assim com algumas importantes lacunas, em especial no que se refere à definição das competências federativas e da titularidade do serviço. A ausência de uma boa organização jurídico-administrativa do setor é, certamente, uma das causas dos péssimos índices de saneamento básico existentes no Brasil.

Os avanços regulatórios verificados permitem, ao menos, a identificação de um Estatuto Jurídico das Águas no Brasil, ainda que, para tanto, tenha sido necessário um esforço hermenêutico e de organização de diferentes normas jurídicas bastante complexo. A simplificação regulatória e a atualização de normas jurídicas extremamente antigas seriam bons caminhos para uma melhoria na gestão dos recursos hídricos no país, no sentido de se garantir a proteção efetiva ao direito humano fundamental à água.

\section{Referências}

BRASIL. Constituição da República Federativa do Brasil. 1988. Disponível em: <http://www.planalto.gov.br/ccivil_03/constituicao/constituicaocompilado.htm>. Acesso em: 15 jun. 2015.

Lei 9.433, de 8 de janeiro de 1997. Disponível em: <http://www.planalto. gov.br/ccivil_03/leis/L9433.htm>. Acesso em: 15 jun. 2015.

. Código Civil. 2002. Disponível em: <http://www.planalto.gov.br/ccivil_03/ leis/2002/L10406compilada.htm>. Acesso em: 15 jun. 2015.

Lei 11.445, de 5 de janeiro de 2007. Disponível em: <http://www.planalto. gov.br/ccivil_03/_ato2007-2010/2007/lei/11 1445.htm>. Acesso em: 15 jun. 2015. CASTRO, J. M. A. y. Regime jurídico das águas no Brasil. Revista do Ministério Público do RS, Porto Alegre, n.65, p.29-36, 2010. 
ESTEVES, C. C. O regime jurídico das águas minerais na Constituição de 1988. 2012. Tese (Doutorado) -Instituto de Geociências, Universidade Estadual de Campinas. Campinas, 2012.

INSTITUTO TRATA BRASIL. Relatório completo 2015. Disponível em: <http:// www.tratabrasil.org.br/datafiles/estudos/ranking/relatorio-completo-2014.pdf>. Acesso em: 15 jun. 2015.

KAUFMAN, D. ONU institui década da água potável. Índice de Sustentabilidade Empresarial, 2012. Disponível em: <http://isebvmf.com.br/index.php?r=noticias/ view\&id=250858>. Acesso em: 15 jun. 2015.

MACHADO, P. A. L. Recursos hídricos: Direito Brasileiro e Internacional. São Paulo: Malheiros, 2002. p.414.

MIRANDA, J. Manual de direito constitucional. Tomo IV. 2.ed. Coimbra: Coimbra Editora, 1998.

ONU. Convenção das Nações Unidas sobre Direitos Econômicos, Sociais e Culturais. 1966 Disponível em: <http://www.ohchr.org/EN/ProfessionalInterest/Pages/CESCR.aspx>. Acesso em: 15 jun. 2015.

ONU. Relatório da Conferência das Nações Unidas sobre a Água. (Mar del Plata, 1425 de março de 1977). Cap. I. Resolução II. 1977

ONU. Declaração de Dublin sobre Água e Desenvolvimento Sustentável. 1992a Disponível em: <http://www.wmo.int/pages/prog/hwrp/documents/english/icwedece.html>. Acesso em: 15 jun. 2015.

ONU. Agenda 21. 1992b. Disponível em: <http://www.mma.gov.br/responsabilidade-socioambiental/agenda-21/agenda-21-global>. Acesso em: 15 jun. 2015.

ONU. Declaração de Viena. 1992c. Disponível em: <http://www.ohchr.org/EN/ ProfessionalInterest/Pages/Vienna.aspx>. Acesso em: 15 jun. 2015.

ONU. Resolução A/RES/64/292. 2010. Disponível em: <http://www.un.org/es/ comun/docs/?symbol=A/RES/64/292\&lang=E. Acesso em: 15 jun. 2015.

UNESCO. Relatório Mundial das Nações Unidas sobre Desenvolvimento dos Recursos Hídricos. 2015. Disponível em: <http://www.unesco.org/new/fileadmin/MULTIMEDIA/HQ/SC/images/WWDR2015ExecutiveSummary_POR_web.pdf>. Acesso em: 15 jun. 2015.

RESUMO - Para construir o desenho do Estatuto Jurídico das Águas no Brasil, foram pesquisadas e analisadas as normas jurídicas internacionais e nacionais que tratam direta ou indiretamente das águas, com enfoque na identificação, nessas normas, dos seguintes elementos: i) grau de reconhecimento jurídico formal da água como um direito humano fundamental no Brasil e no direito internacional; ii) regime constitucional das águas no Brasil; iii) natureza jurídica das águas no direito interno e; iv) garantias jurídicas para a proteção do direito à água. A pesquisa, qualitativa, foi realizada nas páginas oficiais do governo brasileiro e da Organização das Nações Unidas, e as normas selecionadas e analisadas foram aquelas vigentes e que apresentam conteúdo relevante para a construção teórica do Estado Jurídico das Águas. 
PALAVRAS-CHAVE: Direito à água, Direito fundamental à água, Estatuto Jurídico das Águas, Direitos humanos.

ABSTRACT - To build the design of the Legal Status of Water in Brazil, international and national legal standards that address directly or indirectly the waters were researched and analyzed, focusing on the identification of the following elements: i) degree of formal and legal recognition of water as a fundamental human right in Brazil and in international law; ii) constitutional regime of the waters in Brazil; iii) legal status of the waters in domestic law and; iv) legal guarantees to protect the right to water. The research, qualitative, was held in the official pages of the Brazilian government and the United Nations, and the selected laws were those presenting content relevant to the theoretical construction of the Legal Status of Water in Brazil.

KEYWORDS: Right to water, Fundamental right to water, Legal status of waters, Human rights.

Fernando Mussa Abujamra Aith é advogado, professor da Faculdade de Medicina da Universidade de São Paulo (FMUSP). Vice-coordenador científico do Núcleo de Pesquisas em Direito Sanitário da USP. @ - fernando.aith@usp.br

Renata Rothbarth é advogada, pesquisadora do Núcleo de Pesquisas em Direito Sanitário da USP. @ - renata.rothbarth@hotmail.com

Recebido em 16.6.2015 e aceito em 15.7.2015.

I, II Núcleo de Pesquisa em Direito Sanitário, Universidade de São Paulo. São Paulo/ SP. Brasil. 
